\title{
STOCK PREDICTION SYSTEM USING ANN
}

\author{
Mahesh Korade $^{1}$, Sujata Gutte ${ }^{2}$, Asha Thorat ${ }^{3}$, Rohini Sonawane ${ }^{4}$ \\ ${ }^{1}$ Lecturer in Dept. of computer SITRC Nashik, University of Pune, Maharashtra, India \\ ${ }^{2}$ B.E.Student in Dept. of computer SITRC Nashik, University of Pune, Maharashtra, India \\ ${ }^{3}$ B.E.Student in Dept. of computer SITRC Nashik, University of Pune, Maharashtra, India \\ ${ }^{4}$ B.E.Student in Dept. of computer SITRC Nashik, University of Pune, Maharashtra, India
}

\begin{abstract}
Prediction of stock market returns is an important issue in finance. Artificial neural networks have been used in stock market prediction during the last decade. Predicting anything is very hard especially if the relationship between the inputs and outputs are non-linear in nature and stock price prediction is one of them. In this paper we have proposed stock prediction system, in this stock price prediction using multi-layer feed forward Artificial Neural Network (ANN). In this model we have used back propagation algorithm of ANN. As the closing price of any stock market already covers other attributes of the company, we have used historical stock prices (closing) for training the neural network. This paper was aimed at finding the best model for the prediction of Stock Exchange market values.
\end{abstract}

Keywords: Stock market prediction, neural network, back propagation, Client-server architecture, Neuron.

\section{INTRODUCTION}

Normal human tendency is that make its life sophisticated and easier. That's why many people research on technology which makes its life easier. This age of modern generation, in this new technologies are developed to solve human problem. So one of the tremendous task is share market. It is the biggest challenge in front of human to predict its future value because the share market is important factor which affect business as well as human life. Till now there are researches are done in share market field .Like now days many web sites are available for share market to help u ser. But that web site is not sufficient for new user to take a decision about share. Without any guided person he can't take proper decision about share whether it sale or purchase so it may happen that the misguidance by senior person.

So we design such a system which has intelligence like human being. And this type of technology is called as Artificial intelligence (AI).The artificial intelligence technology is inspired by human neural system. The neuron in neural system which is mainly effect in decision making .In this case neurons work is very effective. The science is inspired by this system and develop Artificial Neural Network (ANN) [1].

In this way the artificial neural network (ANN) is used to take proper decision in prediction in share market. Like share market prediction, there is whether forecasting [8]. The weather forecasting is like share prediction .In this also, there is huge amount of data which is in non-linear form. Since also we can predict whether at some level .In share market, by using fix period of interval we can predict the future value of particular share. For that the back propagation algorithm of ANN is used.

\section{RELATED WORK}

The share market is worldwide famous. In it there is large amount investment is happen. The shareholders are investing money in shares. Our India's biggest share market is in Mumbai. And share holders are invest their money in many of these companies. But all share holders are not always stay there to take update about share. So from years ago, there are some web sites are launched in market to give update to share holder at any time where internet is available. That web site are only give information about share market like www.sharekhan.com.So if any new person wants to enter in the share market then that person get information from knowledgeable person who is working in share market. And new person cannot take proper decision about share without guideline of knowledgeable person. And there is no guarantee of that person, there may be chances of misguide line and new person is goes in loss. So there is no software/website that helps to new user. And no one is predicting share value to help new share holder.

Stock market prediction has always had a certain issue for researchers. While numbers of scientific attempts have been made on these issues, no method has been discovered to accurately predict stock price movement [1]. The difficulty of prediction lies in the complexities of modeling share market dynamics. Even with a not having enough of unchanging prediction methods, so there have been some mild successes [6]. 
One area of limited success in stock market prediction comes from linear data. Information from quarterly reports or breaking news stories can dramatically affect the share price of a security. Most existing books and predicted information on financial text mining relies on identifying a predefined set of keywords and special way of machine learning. These methods typically give a task weights to keywords in proportion to the movement of a share price. These types of analyses have shown a decided, but weak ability to predict future event the direction of share prices. In this system we generate share value which is very close to changes in share market using artificial neural network and network is train by data set [10].

We believe that combining more precise textual representations with historical stock pricing information will yield improved predictability results.

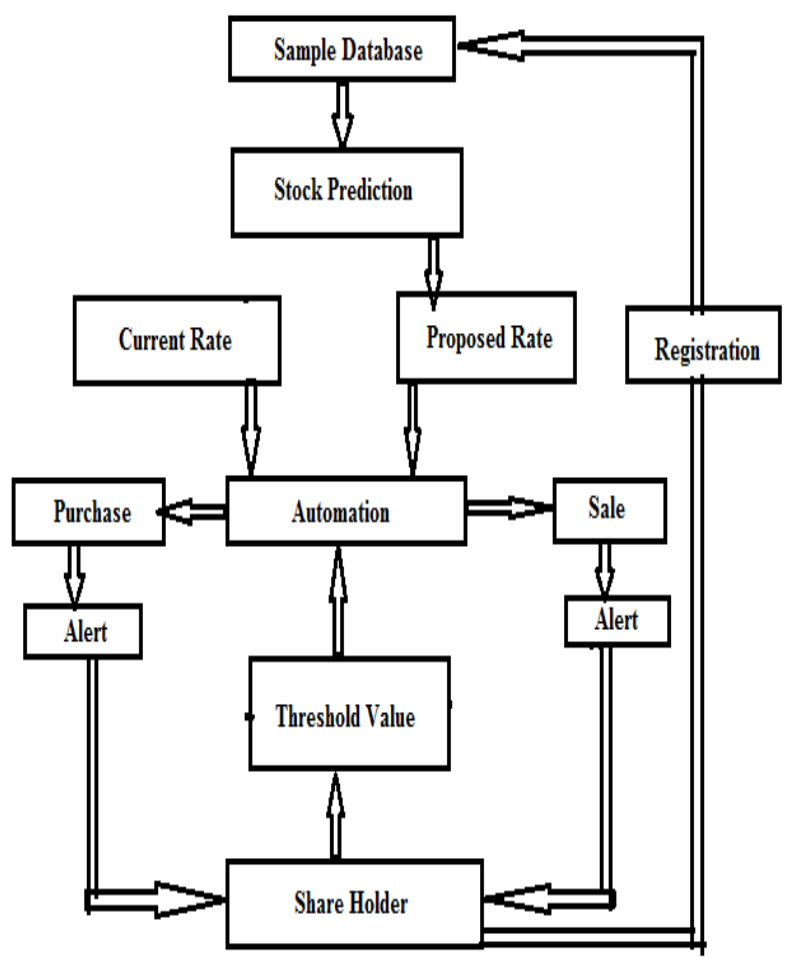

Fig -1: Block diagram of proposed system

The work flow of above block diagram is given below.

1. The share holder as well as company can register itself in database.

2. The Sample database is input to stock prediction system. Here value of share is predicted with the help of history analysis using back propagation algorithm.

3. And predicted value of share is send to user by SMS alert system.

4. The share holder can set threshold value in system to automatically sale or purchase the share. For sale and perches share, it require current rate of that share, so current rate is input to automation.

5. a) If user want to sale particular share at particular value only then he set the threshold value of that share in system. As soon as the current value of share is equal to the threshold or greater then it then automatically share is sale.

b) And if user wants to purchase the share of particular company at particular value then he also set the value of it in system and as soon as the current value of share is less than or equal to the threshold value then that share is automatic purchase. After sale and purchase of share, SMS alerts are automatically send to user.

\section{Algorithm:}

//Problem Definition: How to predict the value of a allowance by considering fixed period of market trend related with allowance of specially great firm.

//Input: Sample database of company, Current Value of share. //Output: predicted values as well as SMS alter.

Step 1: Obtain training patterns set.

Step 2: Create neural network model A: No of Input neurons, neurons of latent layer, Output Neurons.

Step 3: Set learning rate $\eta$ and momentum rate $\alpha$.

Step 4: Initialize all connection $\mathrm{Wji}, \mathrm{Wkj}$ and bias weight $\theta \mathrm{j}$ $\theta \mathrm{k}$ to random values.

Step 5: Set minimum error, Emin.

Step 6: Start training by applying input pattern one at a the Layers after that calculate total error.

Step 7: Through output, hidden layer as well as adapt weight compute back propagate error.

Step 8: Through output, input layer as well as adapt weight compute back propagate error

Step 9: Check it Error<Emin If not repeat Steps 6 to 9. If yes stop training.[15]

\section{METHODOLOGY}

To develop Stock prediction system, it requires some parameter such as follows:

\subsection{Data Set}

To predict any value in any field, it required large collection of data. By that data only system can predict its future value as well as it required to train and validate the neural network. So in this system, we required stock market (share market) data which can take from Yahoo! Finance or IT or Non-IT companies.

\subsection{Data Preprocessing}

The data must be prepared in a format that the neural networks understand it. Because which data we take from various stream that is in non-linear format which is not directly understand by neural network. The performance of neural network is depends on quality of data, therefore data which is fed into the network that must be in well known format of 
network. For that we remove unwanted data from non linear data and then normalized it in range -1 to 1 using min-max normalization technique. Then data is in normalized form which can be fed into the network. After getting output, the output is also in normalized form. So to get actual output, the output is demoralized. To train network, the whole data is categorized into 3 subset: Set of training data, set of validating data, and set of testing data.

\subsection{Creation of Neural Network and Training}

The neural network is created by input layer, hidden layer and output layer. And also neural network is depending on other parameters such as follows:

- Layers in network

- How many neurons in input layer?

- How many neurons in hidden layer?

- Rate of momentum

- Network learning rate

Initially network was created with some initial values. There must be network is train by back propagation algorithm, because it use to improve performance of neural network. To train network it require data set. By that data set network get trained and give correct output after processing input data.

\section{NEURAL NETWORK}

The neural network is made up of no. of neuron. The idea of neuron is arrive from human body. The human body contains number of neurons which contain certain information and that information passes to one neuron to another neuron. The information is some processing output or outside information. In that way the ANN is work .In ANN, there are multiple neurons, if we consider $\mathrm{m}^{\text {th }}$ and $\mathrm{n}^{\text {th }}$ neuron then $\mathrm{m}^{\text {th }}$ neuron functioning output if pass input to $\mathrm{n}^{\text {th }}$ neuron. So the connection weight of neuron $\mathrm{m}$ and $\mathrm{n}$ is denoted $\mathrm{as} \mathrm{W}_{\mathrm{mn}}$ i.e. $\mathrm{W}$ is weight. [14]

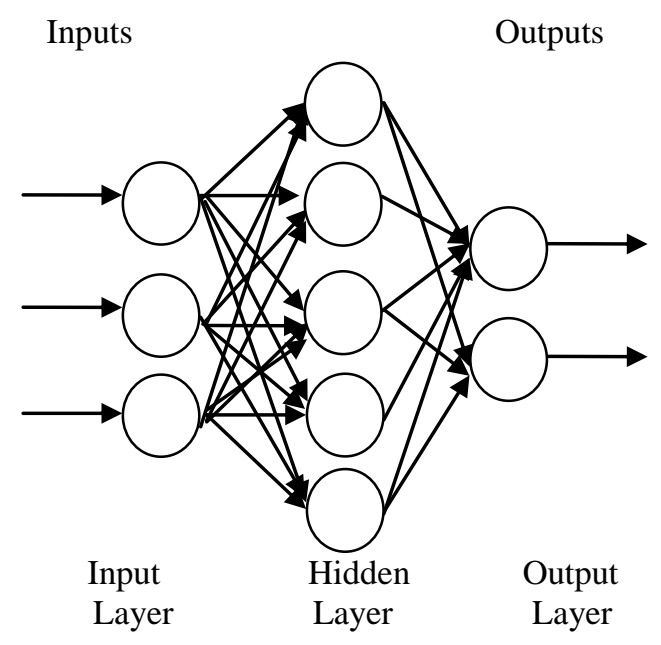

Fig -2: Architecture of a feed forward MLP
In our system, the feed forward multi layer neural network is used. The ANN is made up of layers of neurons. In this, the first layer is input layer which is connected to the input data. After input layer, there could be one or more than one hidden layers called middle layer. And last layer is output layer which gives results. In feedback network, all the connections are toward the output layer. So the feed forward perceptron network is as below.

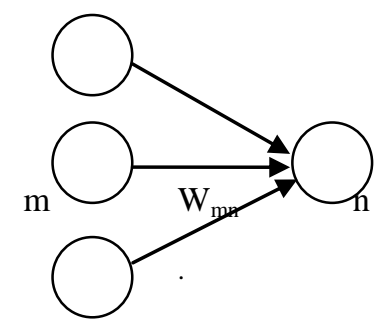

Fig -3: Perceptron neuron's connections.

\subsection{Client-Server Architecture:}

Our stock prediction system is the client server based system. The client server based means the one system is server and other are the client. The database of share market is located at server and client access required data through server URL. For example, as we access Google database through www.google.com URL like this share market user can access share database by using simply URL of system.

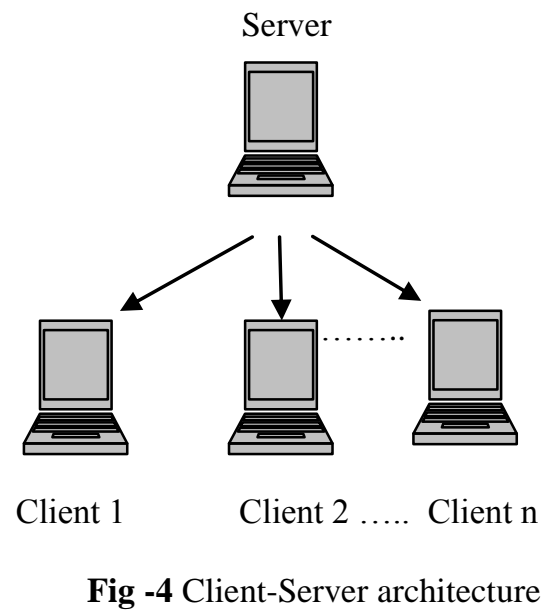

\subsection{Back Propagation}

There is found many colorful history of Back propagation. Without any confusion, recently the most popular and repeatedly used neural network architecture is back propagation. The back propagation networks can learn complicated multidimensional mapping. For computing the necessary corrections the back propagation algorithm is used. in the following four steps The back propagation algorithm can completed : first one is Feed-forward computation second is to the output layer compute Back propagation, third step is to the hidden layer compute Back propagation, forth step is 
updates Weight. When the value of the error function has become sufficiently small the algorithm is stopped.

Till now, hundreds of neural network type has been proposed. Due to this neural surrounding a goal are full extent studied and given different names and you will refer them as ANN. Back propagation is networking itself as well as learning and training algorithm also. This network may be feed forward or Multi-layer perceptions (MLPs). Common method of training artificial neural network is an abbreviation for "back propagation". Back propagation is supervised learning method. Back propagation requires set of data of output for ' $n$ ' no. of inputs and then making the training set. For simple pattern recognition and mapping back propagation networks are ideal. In training there is given algorithm examples of what require doing and it changes the network's weight. That's why when training is finished, for a particular input it will give you the required output [6].

Suppose in network $\mathrm{x}$ is a single real input and $\mathrm{f}$ is network function. Then derivative of $\mathrm{F}(\mathrm{x})$ is computed in two phases Feed-forward and Back propagation. Feed-forward: into the network the input $\mathrm{x}$ is fed. Using this function derivatives are evaluated at every node. Evaluated derivatives are stored. Back propagation: at the output unit the constant 1 is fed and run network in backward direction. All Incoming information is stored and multiplied the value which is stored in the left part of unit. After that the result is propagate to the left part of the unit. Then at the input unit the result is collected.

\subsection{Testing and Training}

Using this system user can predict future value of share. User can set automation for buy or sale the share. For the prediction and automation there is need of company database. Main purpose of this system implementation is prediction. For this first of all given database as a input to the prediction system and input data are must be valid. Because of analysis database system computes the result. if input data are not valid then system cant compute correct result. That's why validity of data is check first and after that valid data are given as an input to the system. For result processing are done on input database. Shareholder decides that which share they want to purchase or sale. User can purchase share of any company whose shares are available in market. And also shareholder decides how many share wants to sale. The automation function is used for automatically sale or purchase share. For example: one shareholder wants to purchase share of Tata company. Then shareholder can set value of no of share they want to purchase and rate of share. And suppose some other shareholder wants to sale the share of Tata company then he set how many share he want to sale and rate of share. Rate of share are continuously changed. Values of share are set by admin so it is centralized process. Admin set value of share and at that time if both value are match i.e. rate of share and no of shares then automatically share is buy or sale share[12].
For knowing future value of share prediction function is available. Prediction is computing by analysis history of database. Back propagation is used for prediction. Shareholder set the value of from how many days they want prediction. Input is given to prediction system by share owner. In back propagation there is used last value of share at everyday and calculates difference between these value of share after that calculate average and this average are add into current value of share value. After addition getting answer is set as prediction value. Thus predict future value of share [12].

\section{CONCLUSIONS}

In this paper we use artificial neural network (ANN) to predict the value of stock share in the next day using the previous history of data about stock market value. The resultant value show that predicting the direction of changes of share values in the next day. In this system we used feed forward MLP neural network predicts the direction of the changes correctly; the amount of change is very close to real share value. In future works, we are going to apply other recently proposed regression method which is newer in the field of machine learning researches e.g. Support Vector Regression model and claimed to have good generalization ability due to application of large margin concept.

\section{ACKNOWLEDGEMENTS}

We are thankful to our Principal Dr. S.T. Gandhe, whose time to time help and valuable guidance gave us high moral support. We would also like to sincerely thank our Cocoordinator of Computer Department Prof. Sandip Walunj for his guidance and constant encouragement. We are also grateful to Prof. Mahesh Korade and Prof. Monika Deshmukh for their encouraging guidance. We are highly obliged to the entire staff of the Computer department and our friend for their kind cooperation and help.

\section{REFERENCES}

[1]. Chen An-Sing, Leung Mark, Daouk Hazem, "Application of Neural Networks to an Emerging Financial Market: Forecasting and Trading the Taiwan Stock Index," Computers \& Operations Research, vol. 30, 2003,pp. 901-923.

[2]. G. Armano, M. Marchesi, and A. Murru, "A Hybrid Genetic-Neural Architecture for Stock Indexes Forecasting," Information Sciences, vol. 170, 2005, pp 3-33.

[3]. Qing Cao, Leggio Karyl, Marc Schniederjans, "A Comparison Between Fama and French's Model and Artificial Neural Networks in Predicting the Chinese Stock Market," Computers \& Operations Research, vol. 32, 2005, pp. 24992512.

[4]. Olson Dennis, Mossman Charles, "Neural Network Forecasts of Canadian Stock Returns Using Accounting Ratios," International Journal of Forecasting, vol.19, 2003, pp. 453-465. 
[5]. C.W.J. Granger and A.P. Anderson, "An Introduction to Bilinear Time Series Models," Vandenhoeck and Ruprecht, Gottingen, 1978.

[6]. G. Grudnitzky and L. Osburn, "Forecasting S\&P and Gold Futures Prices: An Application of Neural Networks," Journal of Futures Markets, vol. 13, No. 6, pp. 631-643, September 1993.

[7]. Zhang Guoqiang, Patuwo Eddy, Hu Michael, "Forecasting with Artificial Neural Networks: The State of the Art," International Journal of Forecasting, vol. 14, 1998, pp 35-62.

[8]. M.J.C. Hu, "Application of the Adaline System to Weather Forecasting," Master Thesis, Technical Report 67751, Stanford Electronic Laboratories, Stanford, CA, June 1964. [9]. Levenberg K., "A Method for the Solution of Certain Problems in Least Squares," Quart. Appl. Math. , no. 2, 1944, pp. 164-168.

[10]. T. Kimoto, K. Asakawa, M. Yoda, and M. Takeoka, "Stock market prediction system with modular neural network," Proceedings of the International Joint Conference on Neural Networks, 1990, pp. 1-6.

[11]. D. Marquardt, "An Algorithm for Least Squares Estimation of Nonlinear Parameters," SIAM Journal of Applied Mathematics, no.11, 1963, pp. 431-441.

[12]. H. Mizuno, M. Kosaka, H. Yajima, and N. Komoda , "Application of Neural Network to Technical Analysis of Stock Market Prediction," Studies in Informatic and Control, vol.7, no.3, 1998, pp.111-120.

[13]. H. Tong and K.S. Lim, "Threshold Autoregressive, Limit Cycles and Cyclical Data," Journal of the Royal Statistical Society Series, vol. B- 42, no. 3, 1980.

[14]. A.S. Weigend and N.A. Gershenfeld, "Time Series Prediction: Forecasting the Future and Understanding the Past," Addison- Wesley, Reading, MA, 1993.

[15]. P.J. Werbos, "Generalization of back propagation with application to a recurrent gas market model," Neural Networks, vol. 1, pp. 339-356, 1988.

[16]. Md. Rafiul Hassan and Baikunth Nath, "Stock Market Forecasting Using Hidden Markov Model: A New Approach," 5th International Conference on Intelligent Systems Design and Applications, 2005.

\section{BIOGRAPHIES}

Prof Mahesh Korde, Author is currently an assistant professor at the Department of Computer Science and Engineering at the University of Pune. His recent work has been in the areas of Advance Database, Software testing and quality assurances.

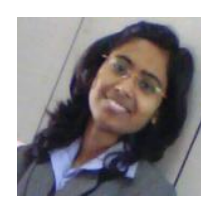
Author is currently a B.E. final year student at the Department of Computer Science and Engineering at the University of Pune. His recent work has been in the areas of Artificial Neural Network.

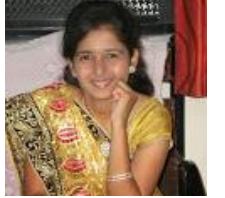

Author is currently a B.E. final year student at the Department of Computer Science and Engineering at the University of Pune. His recent work has been in the areas of Artificial Neural Network.

Author is currently a B.E. final year student at the Department of Computer Science and Engineering at the University of Pune. His recent work has been in the areas of Artificial Neural Network. 